\title{
DE DOCE EJEMPLOS DOCUMENTALES EXPEDIDOS POR EL JUSTICIAZGO DE ARAGON, DESDE EL FONDO DOCUMENTAL DAROCENSE DEL ARCHIVO HISTORICO NACIONAL DE MADRID
}

\author{
M. ' Rosa Gutiérrez Iglesias \\ Universidad de Zaragoza
}

Bajo la impropia denominación de «Cartas reales», pues no siempre sus otorgantes son de condición real, custodia el Archivo Histórico Nacional un fondillo documental de ciento cincuenta y cinco ejemplares entre documentos en tradición original y copias en sus diversas categorías que tiene un destinatario común, la antigua Comunidad de aldeas de Daroca.

La importancia para la historiográfía local que encierran algunas de estas piezas, todas ellas de carácter público, ha merecido la atención de los estudiosos en la materia que han aprovechado sus dispositivos para la elaboración de sus trabajos. Pero el análisis individualizado y pormenorizado de cada una de estas piezas dentro de esa unidad temática que encierran, abre una amplia gama de posibilidades, además de las historiográficas, de tipo paleográfico-diplomático que parece atractivo contemplar.

Así, de este bloque homogéneo de ejemplares documentales despiertan enseguida el interés diplomático doce piezas y originales y una copia notarial coetánea surgidas de la corte de cinco populares justicias del Reino de Aragón: Juan López de Sesé; Domingo Cerdán; Juan Ximenez Cerdán; Berenguer de Bardají y Martín Díez de Aux.

Los ejemplares aparecen expedidos entre los años 1358 y 1434, período de tiempo, pues, casi coincidente con los límites de la etapa más flore- 
ciente de toda la historia del Justiciazgo de Aragón tras las nuevas atribuciones del oficio y autoridad otorgadas en las Cortes de Zaragoza de 1348 y más posteriores de 1371 y 1467 a los magistrados titulares de tal institución.

En cuanto a su condición jurídica los documentos recogidos reflejan, esencialmente, la actuación de los justicias citados en uno de los procedimientos procesales más comunes dentro de sus competencias, el de la concesión de firmas de derecho $u$ órdenes inhibitorias de agravios hechos o, por el contrario, en la anulación de alguna de las mismas.

Otros ejemplares componentes de este grupo son simples autorizaciones de traslados de privilegios solicitados de la curia del Justicia de Aragón por los interesados.

No todas las cartas que se presentan expediddas por el Justiciazgo de Aragón aparecen otorgadas directamente por el justicia del momento sino también por algún miembro del cuerpo de lugartenientes al gozar, como es sabido, de las mismas atribuciones del magistrado citado salvo la del proceso de manifestación, caso no presente en esta documentación recogida.

Los documentos fueron despachados durante los consecutivos reinados de Pedro IV, Juan I, Martín I, Fernando I y Alfonso V por los correspondientes Justicias o por los lugartenientes auxiliares de los mismos, siguientes:

Juan López de Sesé. De la cancillería de este Justicia figura dentro del grupo un único documento de comunicación de «fidancia de directo» otorgado en Zaragoza a 5 de enero de 1358 (1) y dirigido al Justicia de Daroca Jimeno Pérez de Rueda, a su lugarteniente y a algunos oficiales reales, exponiéndoles que se ha otorgado una firma de derecho a los hombres de la Comunidad de aldeas de Daroca y que por tanto deben de cesar toda acción contra sus personas y bienes hasta que se dicte sentencia en el juicio correspondiente.

El tenor diplomático es muy sencillo. Se inicia con una dirección a la que precede un término de cortesía, «Venerabilibus iusticie ville Daroce vel eius locuntenenti ceterisque oficialibus domini regis»; sigue la intitulación del otorgante, «ohannes Luppi de sesse, domini regis consiliarius ac justicie Aragonum», y una fórmula de saludo, "Salutem et gratiam et amicabelem afectum». La exposición de motivos es muy extensa y se desarrolla a partir de la comparecencia de los supuestos agraviados con la expresión del derecho vulnerado por la acción de los destinatarios y la mención de la firma de derecho otorgada como consecuencia de los motivos alegados, «Pro parte hominum universitatis aldearum dicte ville Daroce fuit expositum coram nobis quod ... 
Jacobus ... rex Aragonum ... per se et suos concesit universis hominibus ... aldearum Daroce ... quod non tenerentur in aliquo respondere iudici ..., iuratis, iusticie ... nec eis aliquod servitium facere ullo modo ... Et dictis hominibus dictarum aldearum existentibus, ut prefertur in dicte sua posesione, datum est eis, ut asseritur inteligi quod vos Eximinus Petri de Rueda, iusticie dicte ville Daroce ... indebite ... et contra ... forum ... petitis ... a dictis hominibus dictarum aldearum certam pecunie quamtitatem ... salarii ... oficii iusticiatus ... Ea propter firmatum de directo coram nobis super dicta posesione et de faciendo vobis superpredictis complementum». Disposición comunicando a los destinatarios para que no perturben ni despojen de sus bienes a los agraviados, en este caso, los hombres de la Comunidad de Daroca, por estar a justicia, es decir a las resultas del juicio pertinente, «ld circo ex parte domini regis vobis et unicuique vestrum dicimus quatenus super iurisfirma coram nobis oblata prefatis hominibus ... rationibus predictis minime pignoretis nec aliter contra eosdem vel eorum bona procedatis ...» Por último la data, «Datum Cesarauguste, $V^{a}$ die ianuarii, anno a Nativitate Domini millessimo $\mathrm{CCC}^{\circ} \mathrm{L}^{\circ}$ octavo"».

La validación viene dada únicamente por la aposición del sello del Justiciazgo.

Juan Pérez de Caseda. Lugarteniente del Justicia de Aragón Domingo Cerdán y del hijo de éste Juan Ximenez Cerdán. Otorga firmas de derecho de 28 de agosto de 1388 y 6 de agosto de 1414 respectivamente, y dos autorizaciones de privilegio de 17 de septiembre de 1407.

Es la primera de las firmas de derecho, una copia auténtica que ha llegado inserta en la revocación de la misma hecha en Zaragoza a 8-X-1388. Está extendida a favor de García López de Sesé, baile general de Aragón, reconociéndole las atribuciones que le son propias, conforme a disposiciones de Pedro IV y Juan I, y ordenando que las Comunidades de Aragón se las respeten en punto a la convocatoria de plegas anuales, fiscalización de cuentas y nombramientos oficiales, desarrollándose con el siguiente formulario de: $d i$ rección, intitulación del disponente, exposición con la comparecencia de la persona agraviada, nominación toda de los derechos que le son vulnerados por los destinatarios del documento, reconocimiento por parte del Justiciazgo de estos derechos y, mención del daño inferido, disposición con la notificación de que el damnificado está a resultas del juicio y de que debe de suspenderse toda acción contra él, data bajo el sistema acostumbrado de «Datum Cesarauguste, XXVIII die augusti, anno a Nativitate Domini millessimo $\mathrm{CCC}^{\circ} \mathrm{LCCC}^{\circ} \mathrm{VIII}^{\circ}{ }^{\circ}$. 
En cuanto a la segunda de las firmas de derecho del año 1414 (2) expedida por la oficina del Justicia de Aragón en la persona de Juan Pérez de Caseda, lugarteniente, ahora, de Justicia Juan Ximenez Cerdán, nos cuenta en su dispositivo como se detienen todas las acciones emprendidas contra la Comunidad de aldeas de Daroca por parte de Antón de Luna y Juan de Luna, quienes asumiendo los derechos que detentaba don Jaime, conde de Urgel, a la sazón condenado por el rey Fernando I, pretendía el cobro de 9,000 sueldos jaqueses, importe de 18 caballerías que el padre de don Jaime, don Pedro de Urgel, tenía concedidas sobre la Comunidad de Daroca.

El discurso diplomático se inicia con la dirección que comienza con un término de cortesía «Multum honorabili et provido viro gubernatori regni Aragonum...»; sigue la intitulación de otorgante, «ohannis Petri de Caseda ... tenenslucum pro multum honorabili et circunsoecto viro domino lohanne Eximini Cerdan...»; salutación, «Salutem et peratam»; exposición muy extensa que se desarrolla a la manera de las provisiones reales, a partir de la comparecencia de los agraviados, «Per Sancium Ferdinandi de Lihori ...scribe, procuratoris et hominum comunitatis aldearum civitatis Daroce expositum extitit coram nobis quod dicta comunitas et singulares ipsius cum omnibus et singulis ...", y con las indicaciones todas para solicitar la firma de derecho pertinente; disposición comunicando a los destinatarios de las carta que no alteren, ni dispongan de los bienes de la Comunidad de aldeas de Daroca o de los bienes y personas de sus habitantes, mientras no se ventile el juicio debido. Se cierra el documento con la fecha correspondiente, «Datum Cesarauguste die sex̀to augusti, anno a nativitate Domini millessimo $\mathrm{CCCC}^{\circ}$ decimo quarto».

La validación viene dada por la aposición del sello de placa, desaparecido, de cera roja. El documento fue convenientemente registrado como enseñan las letras de «Registrata» en el dorso junto al cierre.

A petición del procurador de las aldeas de Daroca, Pedro Navarro, Juan Pérez de Caseda en su papel del lugarteniente también del Justicia Juan Ximenez Cerdán autoriza los traslados de las confirmaciones de dos privilegios concedidos por Martín l el 29 de enero de 1407 y el 26 de abril de ese mismo año de 1407, ambos «transumpti» fueron datados en un mismo día y lugar, Zaragoza 17 de septiembre de 1407 (3), y cuyas claúsulas diplomáticas se corresponden y desarrollan de la siguiente manera: notificación, "Noverint universi», exposición, disposición, clausula notarial, «... Dominici Andres autoritate ... domini regis Aragonum notarii publici ... qui huiusmodi transumptum libro transsumptorum curie... iuticie extrahi et scribi feci ... et testes manu propria scripsi cum raso et correcto...», corroboración, «et a maiorem roboris firmitatem ipsum sigillo curie dicti domini iusticie impendenti iussimus comuniri, 
doble data ("datum" y "actum")«... anno a Nativitate Domini millesimo quatrocentessimo septimo die, videlicet, sabbati intitulato decima septima mensis septembris apud civitatem Cesarauguste», «Quod est actum in civitate Cesarauguste anno et die prefixit», suscripciones testificales, «presentibus testibus ad predictam venerabilibus Laurencio de Linas et Antonio d'Arcant...", y signo y suscripción notarial, «... Dominici Andres». Ponen fin a los documentos, cuya «plica» permanece doblada, las siglas de «Registrata» indicativas de su paso por la oficina del registro de cancillería, situadas en el centro interior de aquélla.

Domingo Cerdán. A la magistratura de este Justicia y a la última etapa de su ejercicio como tal, corresponde otra carta ejecutoria datada en Zaragoza a 8 de octubre de 1388 (4) que recoge la revocación de una firma de derecho otorgada a favor del baile general de Aragón, García Lope de Sesé, ya citada, de 28-VIII-1388, comunicando la anulación a la Comunidad de aldeas de Daroca atendidas la sentencia de Juan I y las requisitorias formuladas por Yolanda, reina de Aragón.

El discurso diplomático no ofrece nada de destacable salvo su extensísima exposición de motivos obligada por la condición jurídica de la carta. Los elementos constitutivos de la misma son los siguientes: dirección, «Venerabilibus scribe, procuratori, sesmarii ... oficialibus et universis hominibus comunitatus aldearum civitatis Daroce... »; intitulación del disponente, Dominicus Cerdani, domini regis consiliarius pro ac iusticia Aragonum», salutación, «Salutem et peratam»: exposición con alusión a la firma de derecho concedida que se va a copiar por extenso, anuncio de la inserción e inclusión de la carta con la fianza de derecho otorgada y mención de los motivos para la renovación de la misma una vez conocida la sentencia real; data en la forma: «Datum Cesarauguste octavo die octobris, anno a Nativitate Domini millesimo trecentesimo octuagesimo octavo».

Juan Ximenez Cerdán. Tenemos de este Justicia la notificación de tres firmas de derecho expedidas en Zaragoza en 17 de julio de 1392, 26 de enero de 1397 y 18 de febrero de 1415, además de una autorización de traslado de la confirmación de cinco privilegios reales despachados el 31 de octubre de 1399.

En la carta ordenada en 1392 (5) Juan Ximenez Cerdán, como Justicia de Aragón otorga una firma de derecho en favor de Sancho Fernández de Lihori, procurador de la Comunidad de aldeas de Daroca, y del escribano, sesmeros y prohombres de la citada Comunidad, contra los arrendadores y guardas de las salinas de Remolinos y de El Castellar, prohibiendo atentar 
contra los bienes de aquellos por causa de posibles alteraciones en el régimen de la sal hasta que se celebre el juicio correspondiente.

El tenor diplomático se desarrolla de forma análoga al de los demás documentos de esta misma categoría vistos de: dirección, precedida de fórmula de cortesía, "Venerabilibus quibusvis baiulis generalibus regni ac custodibus salis ...»; intitulación, «lohannes Eximini Cerdani miles, domini regis consiliarius ac iusticia Aragonum»; salutación, "Salutem et peratam»; larguísima exposición de motivos; disposición, en la que en nombre del rey se conmina a los destinatarios a no inquietar ni turbar a los agraviados mientras se encuentren a vistas del juicio pertinente; data, «Datum Cesarauguste, decima septima die iulii, anno a Nativitate Domini millesimo $\mathrm{CCC}^{\circ}$ nonagesimo secundo".

Como único elemento validatorio, el sello adherente de cera roja y pequeño módulo, unos $67 \mathrm{~mm}$., del que no se conserva más que un pequeño fragmento. En el cierre de la carta, la marca del registro de cancillería con las letras de «R(egi)s(tra)ta», en el cierre.

Por la otra notificación de firma de derecho despachada por la curia del Justicia de Aragón Juan Ximénez Cerdán en 1397 (6) se comunica a Berenguer de Cortillos, procurador general de la reina Violante de Aragón, que Blasco Martínez de Bello, jurista y procurador de la Comunidad de aldeas de Daroca se encuentra bajo fianza de derecho y por lo tanto le pide que suspenda el ejercicio de su jurisdicción en la citada Comunidad de aldeas hasta que se celebre el juicio correspondiente.

Las clausulas diplomáticas se corresponden con el tenor de las cartas de este mismo contenido jurídico vistas; así comienza el discurso diplomático con la dirección siempre precedida de expxresiones de afecto, "Venerabilibus et discreto dompno Berengario de Cortillos ...»; intitulación, lohannes Eximini Cerdani...»; salutación de «Salutem et peratam»; exposición muy extensa,con todos los requisitos expresados en las demás firmas de derecho, es decir: comparecencia de los agraviados; presentación por parte de estos mismos damnificados del derecho o privilegios que tienen y de los cuales deben gozar legitímamente, como así lo prueban explicando la vulneración de los mismos por parte de los destinatarios de la carta; mención a estos por el representante del Justiciazgo de que se ha solicitado y concedido una firma de derecho a los agraviados; disposición bajo el requerimiento real de que se suspenda toda acción contra los interesados de las personas o entidad que está a juicio expresando si tienen los destinatarios, causas justas para seguir en su proceder acudan transcurridos diez días después de la recep- 
ción de la carta presente, bien por ellos mismos o por sus procuradores, a la presencia del disponente. Se cierra el documento con la fecha que viene dada como es habitual, en forma tópica y crónica por el sistema, ésta última, de la Natividad, «Datum Cesarauguste, XXVI die ianuarii, anno a Nativitate Domini millesimo $\mathrm{CCC}^{\circ}$ nonagesimo septimo".

Como pruebas validatorias, la aposición del sello del Justicia, hoy desaparecido, de placa y cera bermeja, de pequeño módulo, unos $65 \mathrm{~mm}$. de diámetro, las letras del registro de cancillería, «R(egi)s(tra)ta».

La tercera de las firmas de derecho emanada del Justicia Juan Ximenez Cerdán en 1415 (7) va extendida a favor de la Comunidad de aldeas de Daroca, contra Nicolás de Biota, escriba de ración de Fernando I, quien presentado en el lugar de Mainar ante la Comunidad había pretendido percibir de acuerdo con cartas regias decisorias, la parte correspondiente a una plega de 12,000 florines de oro solicitada por el monarca para ayuda al paso de los infantes, sus hijos Juan y Enrique a Nápoles y Sicilia respectivamente; en virtud de esta firma de derecho apoyada, entre otras razones, en no ser atendibles cartas decisorias expedidas fuera del reino de Aragón, ordena a Nicolás de Biota se abstenga, de momento, a todo intento de cobro, por cualquier vía, de la plega solicitada.

Tenor diplomático de formulario semejante al de las demás cartas de este tipo variando tan sólo ciertos modos de expresión. Dirección, con frase de aprecio, «Honorabile dompno Nicholao de Biota, scriptori racionis domini regis...»; intitulación, del otorgante, «lohannes Eximini Cerdan miles, domini regis consiliarius ac iusticie Aragonum»; salutación de «Salutem et peratam»; exposición con la comparecencia de los agraviados o pedidores de la firma de derecho, «Ad vestram beneplacitum volumtatem per Sancium Ferdinandi deLihori considicum Cesarauguste... procuratoris, scribe ... et hominum comunitatis aldearum civitatis Daroce expositum extitit coram nobis quod...»y las razones de porqué se concede la firma de derecho; disposición comunicando a los destinatarios que suspendan de momento toda acción emprendida contra los agraviados en espera de los resultados del juicio pertinente y mientras estén bajo firma de derecho, en nombre del rey, devolviendo al estado primitivo los cambios habidos por causas de acciones emprendidas, acudiendo si tienen motivo justo para continuar en su actitud a la presencia del Justicia de Aragón en el plazo de diez días una vez recibida la presente carta; data, «Datum Cesarauguste, die XVIII febroarii, anno a Nativitate Domini millesimo $\mathrm{CCCC}^{\circ}$ quintodecimo», siempre tópica y crónica. Al dorso son visibles las señales de registro. Perdura un pequeño fragmento de la leyenda del sello del Justiciazgo, «+ SIGILL...». 
Otro de los documentos originales surgido de la corte de Juan Ximenez Cerdán, constituye diplomáticamente y jurídicamente un traslado acta del año 1399 (8) por el que el citado Justicia autoriza a petición de Blasco Martínez de Bello, procurador de la Comunidad de aldeas de Daroca, el traslado de cinco privilegios confirmados por Martín I en 17 de julio de 1399 a la citada Comunidad de aldeas.

Su discurso diplomático es el siguiente: notificación de tipo genérico, «Noverint universi», fecha unida por «quod» a la fórmula anterior, es crónica y tópica, «... anno a Nativitate Domini millesimo trecentesimo nonagesimo nono, die videlicet veneris, intitulata mensis octobris, apud civitatem Cesarauguste»; comparecencia o manifestación en la que se expresa o consta: la autoridad ante la cual él pide el traslado comparece para rogar su expedición, «coram multum honorabili ac provido viro dompno lohannes Eximini Cerdan milite, domini regis consiliario ac iusticie Aragonum»; la intitulación de los postulantes «compauit venerabilis ... dompnus Blasius Martini de Bello, iurisperitus civitatis Daroce, procurator, scribe ... comunitatis aldearum Daroce»; presencia de los notarios instrumentales, «constitutus cum publico procurationes instrumento confecto in loco de Carinyena VIIII ${ }^{\text {a }}$ die menis iulii, anno a Nativitate Domini $\mathrm{M}^{\circ} \mathrm{CCC}^{\circ} \mathrm{XC}^{\circ}$ primo, per Dominicum lohan Esquierdo.vicinum ...» presentación del original que se pretende trasladar, «et exhibuit, insinuavit seu presentavit eidem domino iusticie quoddam privilegium ... domini Martini ... regis Aragonum ... pergamenum conscriptum eiusque vero sigillo cera rubea in filiis siritis sigillatum». Sigue el anuncio de la copia mediante la expresión, «eius quidem privilegii tenor sequitur sub hiis verbis»; la copia literal del original trasladado, «n Dei nomine pateat universis, nos Martinus, Dei gratia, rex Aragonum...»; la clausula con la narración de porqué causa se ha pedido la realización del traslado, "Quoquidem privilegio regio insinuato ... et presentado dompnus Blasius de Bello ...proposuit dicens quod cum ipse et illi quorum procurator existit nunctio se haberent iuvare de dicto privilegio regio tam in iudicis quam extra, intra dominationem domini regis Aragonum et etiam alibi esset que periculosum ... privilegium huic inde per diversa loca dicti regni ... ducere seu dici facere»; el requerimiento por medio del cual el compareciente pide de la autoridad presente, en este caso, del Justicia de Aragón Juan Ximénez Cerdán, la expedición del traslado en forma que tenga fuerza legal y pueda dar fe en defecto del privilegio original, «ideo requisivit dictum dominum iusticiam, quod de dicto privilegio per notarium infrascriptum curie seu transumptum in publicam formam fidei faceret, ac eidem tradi et liberari mandaret ipsumque actorizaret ac eidem suam auctoritatem impenderet pariterque decretum, ut eidem trasumpto, tam in iudicio quam extra fides plenariam habetur, ut originali preinserto, el mandamiento por el que el 
Justicia dando por vista y recibida la petición ordena a un notario de su curia la expedición del traslado, «Et dictus dominus iusticia visa, audita et intellecta dicte propositione et requisitione per dictum procuratorem sibi facta in continenti mandavit de dicto originali privilegio per notarium infrascriptum trasumptum in publicam formam dicto procuratori fieri et tradi, ac eidem trasumptum actoritate impendidit pariter et decretum sub verbis sequentibus", con el testimonio de las palabras del Justicia directa y literálmente recogidas, reconociendo la legitimidad y vigencia del privilegio original, «Nos lohannes: Eximini Cerdan iusticie Aragonum ... preinserto privilegio regio nobisque exhibito, insinuato et presentato ...ipsoque privillegio regio non viciato, non cancellato nec abolito ...» y la autorización de su traslado garantizando el valor legal de éste, «idcirco presens trasumptum auctorizamus ... ut eidem trasumpum in iudicis quam extra fidem plenarie habetur, ut originali privilegio supra inserto", con unas frases corroborativas de los dispuesto mediante el anuncio de la aposición del sello del Justicia citado, «Et ad maioris roboris firmitatem ipsum sigillum curie nostri impendenti iusimus comuniri». Mención de la fecha ya expresada en el inicio del documento, "Quod est actum in dicte civitate Cesarauguste anno et die prefixis» que cierra la claúsula.

Termina el traslado con la suscripción notarial autógrafa, lo mismo que las dos primera líneas del documento, del notario y regente de la escribanía del Justicia de Aragón, Domingo Andrés, que comprende: la exposición de los testimonios testificales; el signo y titulación del notario citado; el testimonio de que se hizo el traslado conforme al formulario de traslados existentes en la curia del Justicia; advertencia de que parte del documento fue escrito por él personalmente y, finálmente, la salva con la fórmula de comprobación del documento traslado, y el anuncio de la aposición del sello pendiente del Justicia Juan Ximénez Cerdán.

El signo notarial es de módulo grande, siendo su nucleo fundamental un rombo formado por un trenzado de dobles líneas; de los vértices irradian cuatro recetas ornadas con gruesos puntos, dividiendo los trazos horizontales la palabra "Sig + num».

Las siglas de «R(egi)strat(a) fueron escritas en el interior del pliegue con trazo cuidado. El sello pendiente de hilos de cáñamo trenzado no se conserva.

Alfonso López de Luna. De este otro lugarteniente de Juan Ximénez Cerdán y de su cancillería procede únicamente la comunicación de una firma de derecho datada en Zaragoza a 21 de marzo de 1417 (9) dictada a favor de Pedro Ximénez de Urrea, vizconde de Rueda, y a Juan de Luna, señor de Illueca, salvando sus derechos en tanto se ventila el pleito incoado por 
los anteriores contra Alfonso de Gandía, conde de Ribagorza, al que reclaman ciertas caballerías que fueron de Jaime de Urgel y el rey le incautó, entre ellas 18 sobre la Comunidad de aldeas de Daroca, dos de las cuales detentaba el procurador del citado Alfonso de Gandia.

El tenor diplomático se corresponde con los ejemplares de su misma calificación jurídica. La carta fue convenientemente registrada y constancia de ello son las siglas de «Registrata» colocadas en el dorso. Del sello del Justiciazgo, adherente y de cera bermeja, no perduran más que pequeñísimos fragmentos. La falta de la cera permite ver una alusión a la formalización de la carta del notario de la curia del Justicia, «Expedita per / Domingo Andres».

Berenguer de Bardají. De la escribanía de este Justicia emana otra notificación de firma de derecho otorgada en Zaragoza a 16 de septiembre de 1422 (10) a favor de los hombres de la Comunidad de aldeas de Daroca prohibiendo se ejecuten sobre los mismos el cobro de unas pretendidas deudas, al parecer usuarias y basadas en documentos no dignos de fe, hasta tanto no se ventile el juicio corresondiente. El Justicia, Berenguer de Bardajl, apoya su firma de derecho en la misión del Justicia que es defender a los regnicolas aragonesas en sus derechos y amparar los fueros y privilegios.

Todo el discurso diplomático se desarrolla conforme a la pauta seguida en los documentos de igual calidad jurídica vistos. También esta carta fue convenientemente registrada e insinuada en el registro de la cancillería del Justicia de Aragón, llevando las letras indicativas de tal operación en la solapa de cierre del documento al igual que en las demás cartas escritas sobre papel; son letras siempre de gran tamaño y con largos rasgueos de adorno. Del sello adherente de cera roja quedan algunas partículas; sobre si huella puede leerse el nombre del notario que hace la «recognitio» y bajo cuyo avalamiento se expidió el documento, "Anton de Salavert».

Martín Diez de Aux. De su permanencia al frente del Justiciazgo solamente tenemos una muestra documental que por su categoría jurídica constituye la copia notarial coetánea (11) convenientemente legitimada por el notario de la curia del Justicia de Aragón, Antón de Salavert, del traslado de una carta de provisión decidida por Alfonso $V$ en las Cortes de Valderrobres de 1429 sobre el greuge de los privilegios y franquezas del peaje y otros derechos que tenían los nobles y Comunidades del reino. Autoriza el traslado el Justicia de este momento, el citado Martín Díez de Aux, y carece de fecha de expedición, pudiéndose adoptar entonces como lugar de salida Zaragoza, sede de la Corte del Justicia de Aragón, y como año cualquiera de los comprendidos entre 1434-1439, años límites de desempeño de la magistratura de martín Díez de Aux (12). 
El traslado, auténtico y simple, fue sacado de las notas de registro de las Cortes de Valderrobres de 1429 tomadas por el notario Antón de Salavert y expresadas en un estilo indirecto y narrativo de simple noticia. El formulario diplomático es, pues méramente expositivo e informativo, no expedido a ruego de nadie ni con una finalidad expresada en el documento, siendo seguramente la intención de la carta el asegurar la supervivencia del original en una copia simple legítima del mismo.

Se inicia el tenor diplomático explicando la categoría jurídica y condiciones del documento, «Aqueste sumpto et traslat es estado saquado bien e fielment de paravla a paravla», siguiendo la descripción y circunstancias del original trasladado con la expresión de la categoría diplomática del original además de con la nominación del disponente del mismo, el lugar y fecha donde fue determinado y persona jurídica que le dio forma material, «... de donde una sisia feyta entre otras cosas en el processo o registro de las cortes por el muyt eccelent princep, alto e magnifico senyor, el senyor don Alfonso, por la gracia de Dios, rey de Aragón, agora bienaventuradament regnant, a los aragoneses en la villa de Valderrobres, anno a Nativitate Domini millesimo quadringentesimo vicesimo nono, celebradas por mi Anthon de Salavert, notario infrascripto, fayto o accitato «. Sigue la locución que anuncia el comienzo de la copia, «el qual sumpto o traslat es del tenor siguient». Se transcribe a continuación la claúsula que procede del citado registro. «E feyto lo sobredito stando el dito senyor rey en el dito solio o cadira real, et la dita cort e quatro bracos de aquella, plegada et ajustada, el dito senyor rey, atendient que por parte de los nobles varones ... infancones e universidades del dito regno en presencia suya, e de la dita cort, e del dito justicia de Aragón iudge en aquella fuesse dado o possado hun greuge contenient en effecto que como muytos varones, cavalleros, infancones e universidades hayan privilegios, etcetera, etcetera". Aquí concluye la parte del proceso o registro transcrito, terminando la carta con la suscripción notarial del notario Antón de Salavert, con su signo, el testimonio de comprobación y la «salva».

El signo es de pequeño nucleo romboidal con cuatro lóbulos interiores con círculos centrados de adorno y ocho pequeños triángulos externos en alternancia los vacios contra los plenos de tinta, de estos irradian largos trazos, los dos horizontales rematan en las sílabas «Sig» y «no».

Varias y breves notas dorsales figuran en el folio segundo,escritas en escritura cursiva y tinta muy desvaída, «declaracio feyta por el senyor rey don Alfonso en las cortes de Balderoves sobre los peages», "Traslat de la provisión hecha por el senyor rey don Alfonso sobre las franquezas en las cortes que se librant en Valderobres», «sobre el greuge de los privilegios / de los 
fechos», "del peage», además de otras notas recientes de finalidad meramente archivística, «sobre el derecho de peaje», «acuerdo de cortes en 1429 Valderobres».

\section{A MANERA DE CONCLUSIÓN}

Estas cartas provenientes de la institución del Justiciazgo de Aragón obedecen, como previamente se ha indicado, a dos categorías jurídicas distintas de documentos: firmas de derecho o notificación del otorgamiento de las mismas, y autorizaciones de traslados de privilegios; unas y otras en cuanto a sus componentes y fórmulas diplomáticas responden a unos sistemas de gran homogeneidad. He aquí, ahora, una representación de los caracteres más significativos de cada uno de estos grupos de cartas.

\section{a) Firmas de derecho}

Nomenclatura que se ha extraido del texto documental pero que también se podría determinar como la notificación por parte de un determinado Justicia de Aragón o por algún lugarteniente suyo, a la parte demandante de un pleito, que ante la comparecencia de la parte demandada y a petición de ésta, da una firma de derecho que previa la alegación de las causas, supuestamente justas para su concesión, le ha sido otorgada, con lo cual deben de quedar en suspenso todas las acciones emprendidas contra sus intereses por los demandantes hasta la incoación y resultado de juicio pertinente.

Su composición diplomática se reduce a las siguientes claúsulas que mantienen siempre una misma disposición: Dirección, precedida de una palabra o locución de consideración y afecto, son las más usuales, «Venerabilibus et discreto», «Multum honorabilibus et provido viro», «Multum honorabilibus et circunspectis viris», «Honorabili dompno» o «Nobilibus dompno». Intitulación, nombre personal y título del otorgante de la carta. Salutación, invariablemente «Salutem et gratiam et unicabelem afectum». más usada que «Salutem et peratam». Exposición, siempre muy extensa, con la narración de todas las situaciones que motivaron la confección del documento. Se inicia casi sin variaciones con la locución «Ad vestram beneplacitam voluntatem per honorabilem...». Disposición, con la resolución de la parte expositiva, siempre comienza aludiendo a la institución real, «ldcirco ex parte domini regis ... dicimus quatenus super dicta iurisfirma ...». Data, es la última claúsula del tenor diplomático, con la que por tanto, se cierra éste. Sello, es la única prueba vali- 
datoria; se trata del sello del Justicia de Aragón, adherente o pendiente, en función del soporte, con las armas del Justicia que ostenta en ese momento la magistratura.

\section{b) Traslados de privilegios}

Suplicados en la cancillería del Justicia de Aragón para evitar el riesgo de la pérdida o destrucción del original, son autorizados por el propio Justicia o su lugarteniente y garantizados por la intervención autógrafa del notario de la escribanía del Justicia de Aragón. Responden siempre al tipo de "Traslado acta» y son constantes sus elementos y forma diplomática que se desarrolla en la forma siguiente: Notificación, siempre bajo la locución «Noverint universi». Fecha cronológica con mención del año, día de la semana y del mes, y tópica precediendo a la mención del lugar la expresión «Apud civitatem...». Texto expositivo con los elementos propios adecuados al carácter del documento, y la claúsula con los principios constitutivos formales de los últimos acontecimientos para la realización del documento en la que se incluye la corroboración con el anuncio de la validación mediante la aposición del sello del Justicia, siendo siempre la misma fórmula la que se emplea, «Et ad maioris roboris firmitatem ipsum sigillo curie dicti domini iusticie impendenti iussimus comuniri», además de la mención testifical. Claúsula final notarial, extensa y autógrafa, al igual que las dos primera líneas del documento, con el signo del notario, su intitulación, mención de haber cotejado el nuevo documento con el original, y la consignación de la «salva». 

NOTAS

(1) M.A.H.N. Diversos, Comunidad de Daroca. Carp. 43, núm. 23. Original, papel, $281 \times 318$ $\mathrm{mm}$., restos de sello de placa en cera roja de $50 \mathrm{~mm}$. de diámetro del Justicia Juan López de Sesé. Tinta negra oscura. Redacción en latín. Escritura gótica cursiva aragonesa distribuida en un solo bloque. Deficiente estado de conservación.

(2) M.A.H.N. Diversos, Comunidad de Daroca. Carp. 44, núm 123. Original, papel verjurado de $423 \times 300 \mathrm{~mm}$. Tinta negra virada en parda. Redacción en latín. Escritura cursiva corriente aragonesa de módulo pequeño, irregular, angulosa; rasgos prolongados en las letras finales tienden a envolver a la palabra a semejanza de las escrituras cortesanas castellanas. Mala conservación.

(3) M.A.H.N. Diversos. Comunidad de Daroca. Carp. 44, núm. 59. Original, pergamino de $746 \times 554 \mathrm{~mm}$. Tinta negra pálida. Redacción en latín. Escritura corriente aragonesa, angulosa e irregular; las dos primeras líneas del texto, la mención de testigos y la claúsula notarial son autógrafas del notario de la escribanía de Justicia de Aragón, Domingo Andrés. Restos de lemnisco de cáñamo trenzado. Buena conservación.

M.A.H.N. Diversos. Comunidad de Daroca. Carp. 44, núm. 60. Original, pergamino de $480 \times 597 \mathrm{~mm}$. Tinta negra oscura que conserva bien su color primitivo. Redacción en latín. Escritura cursiva corriente aragonesa. Notas autógrafas del notario de la curia del Justicia, Domingo Andrés. Restos de lemnisco de cáñamo trenzado. Buena conservación.

(4) M.A.H.N. Diversos. Comunidad de Daroca. Carp. 43, núm. 33. Original, papel verjurado de $467 \times 480 \mathrm{~mm}$. con una marca de agua consistente en el tema de montes o colinas, ésta corresponde a la variedad de tres cumbres elevadas por encima de una línea horizontal siendo más elevada la cumbre del centro, estando separada de las otras dos por dos depresiones de igual profundidad que no descienden hasta la línea base. Tinta negra. Redacción en latín. Escritura cursiva formada de módulo pequeño y trazos muy agudos; contraste entre gruesos y perfiles. Buena conservación.

(5) M.A.H.N.Diversos. Comunidad de Daroca. Carp. 44, núm. 121. Original, papel verjurado de $412 \times 298 \mathrm{~mm}$. con una marca de fábrica consistente en la representación temática de un pez. Tinta negra pálida. Redacción en latín. Escritura bastarda corriente que se dispone en forma de edicto; es de trazo anguloso con engrosamiento de las partes superiores de los ástiles pefilándose en sus extremos; hay alternancia de trazos gruesos y finos entre los rasgos verticales y horizontales de las letras; perceptible separación de palabras. Buena conservación.

(6) M.A.H.N. Diversos. Comunidad de Daroca. Carp. 44, núm. 122. Original, papel de $365 \times 295$ $\mathrm{mm}$. Tinta negra virada en parda. Redacción en latín. Escritura corriente aragonesa; angulosa, de trazo grueso y densa disposición aunque se respete la separación de palabras; ductus inclinado hacia la derecha; ástiles altos y bajos ampliamente destacados. Regular estado de conservación. 
(7) M.A.H.N. Diversos. Comunidad de Daroca. Carp. 44, núm 125. Original, papel verjurado de $452 \times 296 \mathrm{~mm}$. con una filigrana, tres montes inscritos en un círculo. Tinta negra pálida. redacción en latín. Escritura cursiva corriente aragonesa. Restos sello de placa de cera roja de $67 \mathrm{~mm}$. de diámetro. Deficiente estado de conservación.

(8) M.A.H.N. Diversos. Comunidad de Daroca. Carp. 43, núm 53. Original, pergamino de $583 \times 654 \mathrm{~mm}$. Tinta negra virada en parda. Redacción en latín. Escritura cursiva corriente aragonesa; las dos primeras líneas del texto, la mención de testigos y la claúsula notarial son autógrafas del notario de la oficina del Justicia de Aragón, Domingo Andrés. Regular conservación.

(9) M.A.H.N. Diversos. Comunidad de Daroca. Carp. 44, núm. 124. Original, papel grueso verjurado de $435 \times 293 \mathrm{~mm}$. con filigrana: tres montes, de mayor altura el central, coronados por una más de media luna en tangencia al más elevado de los montes. Tinta negra oscura. Redacción en latín. Escritura corriente aragonesa. Mala conservación.

(10) M. A.H.N. Diversos. Comunidad de Daroca. Carp. 44, núm 126. Original, papel grueso verjurado de $440 \times 296 \mathrm{~mm}$. con filigrana que consiste en una variedad de la denominada "carro" de dos ruedas que se corresponde con el tipo más frecuente. Tinta negra virada en parda. Redacción en latín. Escritura corriente aragonesa. Mal estado de conservación.

(11) M. A.H.N.Diversos. Comunidad de Daroca. Carp. 44. núm.128. Copia notarial coetánea al documento original. Tiene como soporte un pliego de papel grueso verjurado de dos folios sin foliar cuya dimensión es de $300 \times 225 \mathrm{~mm}$., siendo la caja de escritua de $270 \times 140$ mm.; marca de fábrica consistente en el tema de «carro» de dos ruedas. Tinta negra virada en parda. Redacción en romance aragonés. Escritura cursiva aragonesa clara y bien formada, dispuesta a línea tendida guardando muy amplio el espacio interlineal. Amplios y abundantes lazos en los ástiles de las letras que suben o bajan en la caja del renglón. Buena conservación.

(12) Andrés GIMENEZ SOLER, El Justicia de Aragón Martin Diez de Aux, en «Revista de Archivos, Bibliotecas y Museos", III (1899). 